\title{
Seborrhea-like dermatitis with psoriasiform elements
}

INSERM

\section{Source}

INSERM. (1999). Orphanet: an online rare disease and orphan drug data base. Seborrhealike dermatitis with psoriasiform elements. ORPHA:168606

Seborrhea-like dermatitis with psoriasiform elements is a rare, genetic, epidermal disorder characterized by a chronic, diffuse, fine, scaly erythematous rash on the face (predominantly the chin, nasolabial folds, eyebrows), around the earlobes and over the scalp, associated with hyperkeratosis over elbows, knees, palms, soles and metacarpophalangeal joints, in the absence of associated rheumatological or neurological disorders. Cold weather, emotional stress and strenuous physical activity may exacerbate symptoms. 